\title{
Reportability of protocol suspensions
}

The Great Eastern University IACUC always informed the federal Office of Laboratory Animal Welfare (OLAW) about significant animal welfare concerns that the IACUC was investigating. After an investigation was complete, it would inform OLAW of its findings and any subsequent actions taken by the committee. On occasion, the IACUC deemed it appropriate to suspend all or part of a protocol. When this happened, the IACUC would also inform the USDA and appropriate federal funding agencies if the involved species was covered by the Animal Welfare Act (AWA) and its regulations.

Dr. Hillary Banks used hamsters as part of her photoperiodicity studies. She had a well-deserved reputation as an outstanding researcher and an equally well-deserved reputation as a difficult customer of the IACUC. The IACUC previously had issued a warning to Banks about her blatant disregard for following her protocol. The warning contained an ultimatum that all or part of her study would be suspended if any additional study-related problems were verified by the IACUC. True to form, another significant protocol violation occurred, and Banks was called in front of the full IACUC. She readily admitted to the infraction, blaming one of her technicians for the incident, and said that she had suspended the technician without pay for one week and had also voluntarily suspended any further animal work on the protocol. The IACUC thanked her for her cooperation and said that it would get back to her with the committee's decision.

After Banks left the room, Larry Covelli, the IACUC chairman, turned to the committee and announced that because another protocol violation had occurred, he would inform OLAW of the problem and of Banks' remedial actions, if the committee was in agreement with what she had done. However, he added that there was no need to inform the USDA or any federal funding agency, since neither the IACUC, the Institutional Official nor any other university official had suspended the protocol. This bothered some of the members who had had their fill of problems with Banks. They wanted some form of punitive sanctions against her, in addition to the voluntary suspension. Covelli calmly said that punitive sanctions could occur with IACUC approval, and he would inform OLAW of the same, but any such sanctions would be wholly based upon the authority given to the IACUC by the university. Nonetheless, he was adamant that under the AWA regulations, there was still no need to report anything to the USDA.

Do you agree with Covelli that a voluntary suspension of an animal activity by an investigator need not be reported to the USDA and the appropriate federal funding agency; or is any suspension of an animal activity, no matter how it occurred, a reportable action?

\section{RESPONSE}

\section{Reporting may vary}

\section{Judy Daviau, DVM, DACLAM and Troy Wilkins, BS}

Unfortunately, those of us in academic communities are sometimes faced with situations similar to that described above. It is important that the IACUC be well versed in reporting procedures in order to prevent regulatory citations at a later date.

In this circumstance, Great Eastern University is dealing with an individual who has been a challenge to the IACUC. Although there is a great deal of history presented, it is important to consider the facts in the immediate scenario to make a decision on whether the incident is reportable. It is stated that a protocol violation occurred, for which Banks voluntarily suspended any further animal work on the protocol. Covelli, the
IACUC chairman, agreed to inform OLAW. This action is appropriate, as the Public Health Service Policy on Humane Care and Use of Laboratory Animals ${ }^{1}$ requires prompt reporting of any serious or continuing noncompliance with this Policy, any serious deviation from the provisions of the Guide or any suspension of an activity by the IACUC (IV.C.6 \& 7 and IV.F.3 \& 4). Therefore, even though the activity was not suspended by the IACUC, reporting is required owing to the deviation from the approved protocol.

The question of whether this matter needs to be reported to the USDA is somewhat different. Even though hamsters are a regulated species, this does not in itself mandate reporting. The USDA requires notification when an activity has been suspended by the IACUC ${ }^{2}$. Because the IACUC did not suspend the activity, this threshold has not been breached. Voluntary suspension of work by the investigator is not addressed in the AWA, and discussions with our Veterinary Medical Officer have indicated that it is not reportable.

Reporting suspensions of animal activity to other funding sources can vary. It is imperative that the sponsorship agreement between the institution and the funding agency is reviewed for specific terminology on this issue. Again, Great Eastern needs to differentiate between a voluntary cessation of activity and an IACUC-mandated suspension. A recent review of agreements with the Centers for Disease Control and Department of Defense at our university showed that the default terminology referred to the AWA requirements. Thus, in this case, voluntary cessation of activity would not be reportable.

One caveat supersedes this entire discussion: Great Eastern University is bound by its PHS Assurance Statement. Reportable actions are clarified in that document. If Great Eastern has indicated that it will report all protocol violations to the funding agencies, it must abide by that statement and report 